\title{
Land Use as a Criterion for the Selection of the Trip Starting Locations of Park and Ride Mode Travelers
}

\author{
Jairo Ortega1*, Dimitrios Rizopoulos, János Tóth¹, Tamás Péter² \\ ${ }^{1}$ Department of Transport Technology and Economics, Faculty of Transportation Engineering and Vehicle Engineering, \\ Budapest University of Technology and Economics, H-1111 Budapest, Múegyetem rkp. 3., Hungary \\ 2 Department of Control for Transportation and Vehicle Systems, Faculty of Transportation Engineering and Vehicle Engineering, \\ Budapest University of Technology and Economics, H-1111 Budapest, Műegyetem rkp. 3., Hungary \\ *Corresponding author, e-mail: ortega.jairo@mail.bme.hu
}

Received: 04 May 2020, Accepted: 23 August 2021, Published online: 01 December 2021

\begin{abstract}
In the attempt to study Light Rail Transit (LRT) systems, and their necessary underlying components, such as Park and Ride (P\&R) sub-systems, this article aims to showcase the importance of land-use as a criterion in the selection of trip starting locations (i.e., points), that can potentially be used as the basis for quantitative studies on LRT and P\&R systems. In order to achieve this goal, a method is introduced for the selection of locations that produce P\&R mode trips based on the land-use attributes of sub-zones or neighborhoods, as they are included in Sustainable Urban Mobility Plans (SUMPs). Those land-use attributes are utilized as sub-criteria for the classification and valid selection of trip starting locations out of a broader dataset of available locations. As a second supportive technique that needs to be utilized for this study, an algorithm is introduced, which allows us to test the effectiveness of the method and the importance of land use as a criterion. The algorithm enables the calculation and comparison of the attributes of the trips to be followed by P\&R mode users starting from selected trip starting locations for each zone in a city and having as destinations the several available P\&R facilities. Results for the methods introduced in this article are showcased based on a case study on the mid-sized city of Cuenca, Ecuador, in which, several metrics, such as traveling times considering different traffic scenarios, are examined for the potential P\&R mode trips as they emerge from real-world data.
\end{abstract}

\section{Keywords}

land use, trip starting locations, classification, park and ride systems, traffic

\section{Introduction}

As it is widely considered, Light Rail Transit (LRT) systems have played an essential role in the encouragement of the shift of passengers from private vehicles to public transportation. Especially in modern metropolitan urban environments, the need for their implementation and use has been crucial for the sustainability and the proper function of those environments. Similarly, the establishment of such systems has been prioritized in urban contexts and mid-sized cities, as in the case of Cuenca, Ecuador. The local authorities of those cities have developed a series of projects, as described in the corresponding Sustainable Urban Mobility Plans (SUMPs) (Hermida et al., 2015), to facilitate the better use of LRT systems. For instance, such a project is a Park and Ride (P\&R) facility, which allows the potential users of the LRT system to utilize their private vehicles in order to reach one of the P\&R facilities, while those facilities provide parking lots for several automobiles, at the same time they serve as access points to the public transportation system (tram, bus, and metro).

The strategic placement and design of $P \& R$ locations is of significant importance to the long-term success of the LRT. The several decisions that need to be taken may have a substantial impact on traffic congestion, air pollution of the urban environment, and the LRT system ridership. Since all of the factors above can either prove the utility of the LRT systems to be high or catastrophically low, their study is of great value. Scientific methods have proven to be unique tools that provide evidence for any of these measures to be taken when designing or implementing such a system. In previous articles, in the attempt to develop useful insights for the expansion of the transit market in Cuenca, Ecuador, researchers (Ortega et al., 2019) have determined a series of 
seven locations and an estimation of the number of parking lots that should be created per site in order to cater to the parking demand of users along the LRT corridor.

Next, an overview of the literature on P\&R systems will be provided. Since the 1930s in middle-sized cities, P\&R systems are commonly referred to as an essential component of sustainable development policies for the shortterm, middle-term, and long-term planning horizons. Transportation planning approaches for P\&R systems (Noel, 1988) usually involve the evaluation, assessment, design, and sitting of the facilities in order to increase the number of users of public transport and reduce traffic congestion and air pollution in the urban environments. Very importantly, and concerning the work presented in this paper, P\&R systems have been included in SUMPs (Cairns, 1998) for cities in an attempt to reduce the undesirable effects of the use of private vehicles. P\&R systems are discussed and presented alongside other essential transport systems, such as rapid transit metro systems, or urban planning attributes of a region, such as land use. However, the relationship between all those parts of SUMPs is not clear yet.

Studies that focus on the design of P\&R systems according to several parameters exist in the literature. Farhan and Murray (2008) suggest that locating park-and-ride facilities is essential when planning for P\&R services. The authors focus on three major siting concerns that need to be addressed when sitting park-and-ride facilities: covering as much potential demand as possible, locating park-andride facilities as close as possible to major roadways, and siting such facilities in the context of an existing system. In another study by Song et al. (2017), an integrated model for locating P\&R facilities, designing the capacity of those facilities, as well as the transit frequency is proposed. The effectiveness of this approach, which is comprised of the mathematical problem and the solution algorithm, is showcased through numerical examples to demonstrate the net social benefit that can emerge from the design of P\&R facilities with this approach. Another important work in the field of P\&R design is the work by Bogler et al. (1992), who introduce a set of rules and guidelines based on operating experience of the Calgary LRT System in Alberta, Canada. P\&R literature can be considered to include also studies that focus on parking activity and facilities, such as the study by Lam et al. (2006), who propose a time-dependent network equilibrium model and a heuristic algorithm for its solution. The model considers the travelers' choice of departure time, route, parking location, and parking duration in road networks. It is found that parking behavior is significantly affected by travel demand, walking distance, parking capacity, and parking charge.

Further research has also been conducted regarding P\&R systems utilization, such as the work by Syed et al. (2013), where the authors determine several characteristics of the system, such as parking demand accumulation, occupancy, duration, turnover, and volume. The authors, in the case studies presented, show that additional measures could be taken in order to increase the utilization of facilities across parking areas of the same P\&R facility. However, P\&R and LRT systems' ability to reshape urban mobility and land use has been previously criticized. Sometimes the benefits of the establishment of an LRT system can be exaggerated by politicians and policymakers. For example, they often tend to cite land-use change as a primary motivator for investment in such systems. However, research (Knight and Trygg, 1977) in P\&R systems for at least the last 40 years has shown that significant land-use change, at least at the short-term horizon, is questionable. Additionally, as stated in the article by Higgins et al. (2014), if an LRT is expected to have high levels of initial ridership, it should be located across areas that will provide those high levels of demand for the short term horizon.

In most modern SUMPs, it is a common practice to include a land-use classification that generally regards a correspondence of natural or urban environment to specific function attributes, such as residential, heritage, commercial, educational, governmental, public, religious, and health functions, with this classification being different from city to city (Un-Habitat, 2013). In our study, we utilize those attributes of land use as included in SUMPs for the further filtering of locations that can be possibly included as trip-generating locations in a study of P\&R mode trips. This filtering can be extended and applied to any public transport system. The reason for developing the method based on the land use criterion is that, based on previous research, we have found that land use plays an essential role in the mode choice of travelers and overall demand for transportation. Given that it has been widely accepted by the scientific community that land use is not independent of the transportation or traffic system and that it overall affects the transport options made available (Aguiléra et al., 2013), as well as the movements of freight and passengers (Rodrigue et al., 2016), in this article we examine and prove the observation that land use characteristics, as established in a SUMP, are an essential factor in determining the origin trip points (i.e., trip generating/starting points) for the potential demand of P\&R facilities. Since 
P\&R mode trips that stem from different locations tend to have different attributes, such as distance covered and travel time, our method is of particular interest for quantitative studies and is a great tool that enables further research.

In a more general context, and similarly to land use, the intention of the trip is also considered to play an essential role in the travel mode choice of travelers in the literature (Milosavljevic and Simicevic, 2019). In a work developed by Abdul Hamid et al. (2008), it is stated that in their surveys, $62.3 \%$ of travelers parked their cars in P\&R stations while they were on a work trip. Other studies also show that a high percentage of the utilization of P\&R facilities stems from work purposes (Adnan and Hamsa, 2013). Finally, worth mentioning is the fact that it can be noticed that in other recent articles (Zhou et al., 2019b), the daily P\&R commuters are considered as user groups in the studies, while $\mathrm{P} \& \mathrm{R}$ usage is also considered as an extra mode of transport called P\&R mode.

Observations also exist for the relationship between existing parking spaces and land use. In the study by Bakogiannis et al. (2018), which was conducted in the Municipality of Zografou in Athens, Greece, the relationship between commercial land use, residential land use, and parking spaces is highlighted. Other studies exist that connect residential and commercial land use to the use of $\mathrm{P} \& \mathrm{R}$ mode. This connection can be broken down into two parts:

1. P\&R demand depends on car ownership and parking demand (Farhan and Murray, 2005; Douglass and Abley, 2001) and,

2. The need for P\&R facility itself to serve areas with specific functions or land uses (Farhan, 2003; American Association of State Highway and Transportation Officials; Bolger et al., 1992).

Especially in the survey published by the Rio Metro Regional Transit District (Rio Metro Regional Transit District, 2012), the relationship between P\&R stations and surrounding land uses is highlighted, with residential and commercial land use being the most prominent. Apart from land use, interesting studies on car usage, parking spaces, and their availability can be found, such as the one by Yin et al. (2018), where the authors examine the impacts of the built environment and parking availability on car commuting. The results of the study indicate that the use of cars for attending the workplace is connected to the availability of parking and built environment and that, on a policy-making level, transit-oriented urban expansion should be prioritized.
With all those observations in place, the authors of the current paper think that the creation of a systematic way for the classification of locations (i.e., sub-zones/neighborhoods), and thus possible trip-generating points, as they are included in SUMPs, is of great need in the literature and can fill the research gap for further computational studies that up-to-now have used random points or random neighborhoods for the calculations of results.

To the best of the authors' knowledge, there are no articles in the literature of P\&R that directly address the study of P\&R mode trips and how the valid selection of their initial starting points can be more effective. The contribution of this article lays in three aspects:

1. It is shown that the selection of trip-generating points based on land-use and subzone/neighborhood data, as included in SUMPs, is essential for the study of P\&R mode trips;

2. A method is provided for valid selection of locations or trip generating points that represent the starting locations of travelers that potentially use P\&R mode;

3. It is showcased that the impact of traffic on the trips to be followed by the P\&R mode users to the corresponding facilities for the case of the mid-sized city of Cuenca is negligible.

In order to support the contributions of the article, a method for the effective selection of P\&R trip-generating locations is derived, as well as an algorithm for the calculations of metrics of P\&R mode trips, as they can be possibly conducted in an urban environment. While the algorithm can be considered as a technique, the method itself can be regarded as the second contribution of this article, as introduced in Section 2, where observations from the literature of $P \& R$ are combined in order to derive this scientific procedure that is used to decide on how to filter the subzones/neighborhoods. The sub-criteria that are used require that the necessary information is included in the Sustainable Urban Mobility Plan (SUMP), surveys, social media data (Lopez et al., 2019), or digital participatory mapping actions (Weyer et al., 2019).

For the first and third contributions, the method and the algorithm are combined to provide a case study where, with the use of modern routing software, we calculate the attributes of P\&R mode trips that start from different initial points and always have as a destination the same nearest P\&R facility. The different sets of points used as the trip starting locations are: 
- Randomly generated starting points in each zone (with the use of Geographic Information System (GIS) software and the shape characteristics of zones \& sub-zones);

- Central points of subzones/neighborhoods in each zone as they are included in the corresponding SUMP;

- Central points of subzones/neighborhoods in each zone after they are filtered according to land use, as included in the corresponding SUMP.

The results of the calculations show that the trips, and the overall accessibility to P\&R locations, can be different across those three cases of input points. The algorithm that is introduced calculates the nearest facility to each of the zones for Cuenca, Ecuador, for each weekday based on real traffic data. The parameters that are considered for the algorithm are the trip-generating points(any of the sets), the traffic situation of five weekdays in a week, and the P\&R locations (see Table 1) that were calculated and proposed by Ortega et al. (2019) in their previous article. A fundamental part of the algorithm is the underlying components that were used that are based on modern routing software (TriMet, 2011; Google Inc. n.d.) and spatial mathematics techniques. Similar techniques were used in literature about providing routing (Bast et al., 2016; Saharidis et al., 2017; Péter and Fazekas, 2014) and navigation to passengers. The method and algorithm are independent of the spatial context and can be applied to any city. Also, instead of those P\&R locations that are proposed for the prospective $\mathrm{P} \& \mathrm{R}$ system in Cuenca, any $\mathrm{P} \& \mathrm{R}$ system's locations can be considered in correspondence to the general spatial context of a case study.

Regarding the third contribution, the main insights are also extracted from the case study, where the travel times of the calculated trips and the nearest P\&R facility across different weekdays are compared in order to

Table 1 The park and ride locations as calculated in previous literature (Ortega et al., 2019)

\begin{tabular}{lccc}
\hline ID & P\&R facilities name & Latitude & Longitude \\
\hline A & Control Sur & -2.923399 & -79.0382343 \\
B & Banos & -2.9147923 & -79.038227 \\
C & Feria Libre & -2.8956061 & -79.0268517 \\
D & Canirabamba & -2.9066296 & -79.0293574 \\
E & Totoracocha & -2.897063 & -78.9902306 \\
F & Aeropuerto & -2.8861158 & -78.9929826 \\
G & Parque Industrial & -2.881886 & -78.9776599 \\
\hline
\end{tabular}

acquire insights about the traffic. This comparison stems from the comparison of results with the same set of origin points, while the second contribution regards the comparison of the results across the application of the algorithm to three sets of input trip starting points. For our case of the middle-sized city of Cuenca, Ecuador, it is shown that the effect of traffic can be negligible.

In that regard, the description of the method, the algorithm, and the software used for the calculation of the trips to the nearest P\&R facilities is included in Section 2 of the article. The case study on the city of Cuenca, Ecuador, is included in Section 3. Finally, a final concluding section is provided with an overview of this work.

\section{The method elaborated and the techniques used}

This section is divided into two parts, Subsection 2.1 and Subsection 2.2. In Subsection 2.1, we discuss our method and the details for selecting the trip-generating locations for the potential trips of the P\&R mode users according to criteria. Then, for Subsection 2.2 of this section, we present the algorithm, and the corresponding set of techniques, for calculating the nearest P\&R facility to each of the zones for the different weekdays, sets of points and metrics, and according to the optimal trips to be followed based on real traffic conditions.

\subsection{The method elaborated for the selection of the trip- generating points}

As it is widely known, in SUMPs, each zone, subzone, or neighborhood is analyzed, and then it is assigned with several characteristics concerning land use. Our method essentially makes use of the available data on the attributes of the zones and sub-zones of a city, as they can be measured by surveys, or, as they are included in SUMPs. In general terms, on the one hand, in any SUMP, we can have formal land-use attributes assigned to a location, which refer to the qualitative characteristics of the area. On the other hand, we can have functional land-use attributes assigned to a location corresponding to its socio-economic function. As a simple example, while one location can be indicated as a school area according to its formal land-use attribute, it can also be classified as educational or institutional for its economic function and functional land use. Usually, those sub-zones or neighborhoods are parts of the several corresponding zones or broader regions of the city.

The analysis of P\&R systems is considered difficult because their utilization is dependent on the accessibility of the P\&R system itself, but also on the transit services quality 
offered; thus, the relationship between trips generated for the P\&R mode from the several zones of a city to other locations does not solely depend on the P\&R system but other adjacent systems. This phenomenon has yet led to a gap in the literature of P\&R that directly connects specific land use to the utilization or establishment of P\&R systems. However, according to the several observations and references, as they are included in the introduction of this article, the authors support the claim that P\&R mode trips tend to have their starting points in zones, subzones, neighborhoods, or, in general, regions that are designated with residential or commercial land use. Based on this idea, the selection (i.e., filtering) of points in our method is based on residential and commercial land use. As discussed previously, this connection can be broken down into two parts:

1. P\&R demand depends on car ownership and parking demand (Farhan and Murray, 2005; Douglass and Abley, 2001) and

2. the need for $P \& R$ facility itself to serve areas with specific functions or land use (Bolger et al., 1992; Farhan, 2003; American Association of State Highway and Transportation Officials; Rio Metro Regional Transit District, 2012).

For the practical selection of points (i.e., locations) that create the demand for P\&R mode, those the two types of functional land use mentioned above were considered as the selected sub-criteria and primarily used to filter the subzones and reduce them from an initially vast number to a smaller, more effective sub-set. This selection is comprised of a multi-step process that requires the handling of geospatial data and the corresponding shape characteristics of administrative regions, on the one hand, and on the other hand, it requires the filtering of those administrative regions according to a scientifically-backed method. Regarding the filtering: out of the data that are included in the SUMP about the city that is under study, we can then cluster the locations (i.e., subzones, neighborhoods) into groups that are described by the same land use; Next, we keep only the locations that are designated in the SUMP as commercial or residential land use areas. For example, in the case of Cuenca, Ecuador that is analyzed in the case study in Section 3 of this article, the SUMP describes in detail the administrative divisions in Cuenca, Ecuador, and the land use for each region. Cuenca is divided into 15 zones, and those 15 zones are then subdivided into 982 subzones or neighborhoods.

The term subzones and neighborhoods are used in the Cuenca SUMP in order to dictate the same spatial context, region, or administrative division. Let us remind the reader that subzones/neighborhoods are parts of the broader zone divisions. While those neighborhoods can have several Formal and Functional land-use properties, due to the supporting literature, we propose the criterion of Functional Land Use of each subzone/neighborhood for the selection of origin points of P\&R trips. As mentioned above, it is generally associated with the socio-economic function of the area and not the qualitative attributes or the real estate developed. According to attributes data for this criterion, we can have several sub-criteria. In the case of the SUMP of Cuenca, Ecuador:
1. Residential use
2. Commercial use
3. Recreational use
4. Agricultural use

The method aims to not vastly reduce the number of candidate origins locations, but rather, to choose the most suitable starting sub-zones (i.e., locations) which generate trips that utilize the P\&R facilities. For example, we assume that the sub-zones that are characterized for recreational and agricultural land use, do not create trips for the $\mathrm{P} \& \mathrm{R}$ mode trips, because the individuals involved with those types of activities tend to prioritize the use of other modes of transport over private vehicles that can utilize the parking facilities. Also, there are no studies in the literature that support that regions that are characterized by other types of land use, except for commercial or residential, tend to serve travelers that are likely to use P\&R mode.

As previously mentioned, the subset of sub-zones produced by our method is independent of spatial context; the method can be applied to any urban environment, and then it can be used to study any aspect of the P\&R system or city. We also believe that the method can be extended with respect to any public transport system, given that the supporting literature for the relationship between land use and trips generated exists in the literature. Moreover, the sub-criteria can differ according to the modelers' preferences, case of study, and the available data. In Figs. 1 and 2, we provide a map of the mid-sized city of Cuenca, Ecuador, depicting the tram line, the $\mathrm{P} \& \mathrm{R}$ locations, as proposed in work by Ortega et al. (2019), and the zones of Cuenca.

\subsection{The algorithm and the techniques used for the comparison of $P \& R$ mode trips}

In order to showcase the effectiveness of the method and role of land use in selecting trip generating points, 


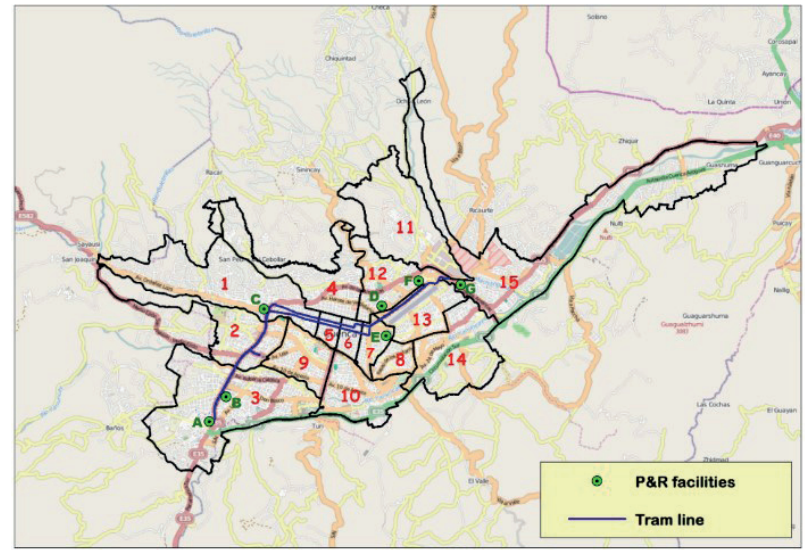

Fig. 1 Zones, P\&R facilities, and the Tram line in Cuenca, Ecuador

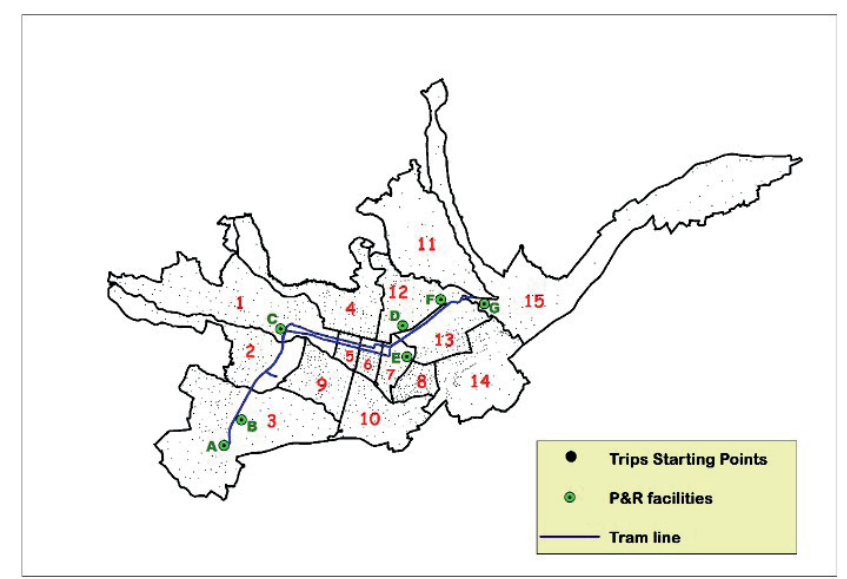

Fig. 2 The set of trip-generating points after the initial set is filtered according to land-use (third set of points in the case study)

we introduce an algorithm that can be used to calculate several metrics for the optimal trips from sets of starting points (i.e., locations) of travelers for each zone in a given city to the P\&R facilities available in the region. The algorithm combines various software libraries and data analysis techniques utilized to perform several tasks. One critical function of the algorithm is the routing engine that calculates the trips and their attributes. In order to study and compare the P\&R mode trips for different sets of starting points, we need to apply the algorithm three times, each time with different input of trip starting points.

Furthermore, in order to efficiently study the P\&R mode trips, we assume that the travelers follow optimal or near-optimal trips as they are calculated by the routing subroutine (TriMet, 2011; Google Inc.) included in the algorithm. Based on this assumption, we first calculate and then compare the following metrics between the cases of input locations of travelers and the P\&R locations:

1. Direct Haversine distance;

2. Road network distance;
3. Travel time, without traffic;

4. Travel time when low-traffic conditions are in the network;

5. Travel time when high-traffic conditions are in the network.

Those metrics were chosen because they are widely considered to be indicators of accessibility of locations. Regarding the resulting tables of the algorithm that is applied, the average distances and travel times between trip starting locations in each zone and P\&R facilities are calculated. The results for one run of the algorithm are calculated for each zone, each weekday, and the five metrics (or quantities), as mentioned in the list above. While this calculation and the results tables, as included in Section 3 and the case study, refer to the matching of the nearest P\&R facility to each zone, in order to showcase the effectiveness of the method, the algorithm needs to be applied three times for the same zones, same traffic levels but for different points within the zones of the urban region. Those points can be either random points in each zone, central points of subzones/neighborhoods as they are included in the SUMP, and then, finally, the central point of subzones/neighborhoods as they are included in the SUMP after they are filtered according to land use.

Regarding the steps of the algorithm and the calculations as they are described in Table 2, the distances and travel times are calculated from all points (either of the three sets) to all P\&R facilities, as described in Table 1. Then the average distances and travel times for each zone are calculated, and then the minimum value for each average metric across all the P\&R facilities for each weekday. This minimum value corresponds to one P\&R facility, which is kept for each weekday and metric (i.e., calculation quantity) and considered as the nearest facility. Regarding the averages of the aforementioned quantities for each zone, they are calculated by summing up the distance or the travel time from the starting points for each zone by the corresponding step of the algorithm and then dividing this sum by the number of points in this zone. For the trip starting points that stem from the SUMP, the number of sub-zones considered for each zone is different.

The final result of the application of the algorithm and the techniques (i.e., subroutines) for each set of input starting locations is a table containing the nearest $P \& R$ facility to each zone per metric and day. In this way, from a single table, we can extract useful insights about the system and how the optimal trips are followed by the potential users 
of P\&R mode deviate from day to day and according to the level of traffic. If many changes concerning the nearest facility to each zone are presented in the results matrices according to several metrics and weekdays, this means that the effect of traffic may lead to deviation in the traveler's behavior day by day. Also, the resulting tables across different sets of points can be compared between them, but in this case, we can deduct insights about the effect that the different sets of trip starting points have on the calculations. For this second comparison, if significant differences exist between the result tables for different sets of points, this means that selecting the trip-generating points based on land use actually has an impact on the results of the analysis. Both of these comparisons are made in our case study, and they regard the second and third contributions as they are described in the last paragraphs of the introduction for this paper. In Table 2, we provide a detailed explanation of the steps of the algorithm.

For the quantitative calculations included in the algorithm, two other subroutines have been used, one for calculating the direct distances and the other for calculating the rest of the metrics (road network distance, travel time with no traffic, travel time with low-traffic, travel time with high traffic). For the former, we used the Haversine formula, which is used to determine the great circle distance between two locations on a sphere, given their coordinates. In contrast to more simplistic mathematical formulas for calculating direct distances based on coordinates, the haversine formula is based on spherical trigonometry and produces more accurate results. $d=2 r \arcsin \left(\begin{array}{l}\sqrt{\sin ^{2}\left(\frac{\varphi_{2}-\varphi_{1}}{2}\right)} \\ +\cos \left(\varphi_{1}\right) \cos \left(\varphi_{2}\right) \sin ^{2}\left(\frac{\lambda_{2}-\lambda_{1}}{2}\right)\end{array}\right)$

As included above, Eq. (1) represents the Haversine formula. Given two points on a map, Eq. (1) calculates the direct distance between the two points, where $\varphi_{1}, \varphi_{2}$ is the latitude, and $\lambda_{1}, \lambda_{2}$ is the longitude of the two points. The haversine formula is utilized in numerous studies (Whitsel, 2004; Esenbuga et al., 2016; Winarno et al., 2017) across many fields of science. In the study by Esenbuğa et al. (2016), it is shown that across several distance calculations methods, the Haversine formula is characterized by a Relative Percentage Error of $0.2 \%$ when compared to the most accurate methods available. However, since that error won't affect the results of this paper, and consequently the conclusions, and since Haversine is a lightweight, in terms of computing power, and comprehensive formula, it has been chosen for the facilitation of this study over other approaches.

The second subroutine of the algorithm that was used is the Google Maps Directions API Service (Google Inc. n.d.). It was utilized as an external source of information for the algorithm to produce the real road network measurements for the travelers that are potentially using their private vehicles (i.e., cars) to use the P\&R facilities. While the exact way in which the Google Maps Directions Service calculates the traffic conditions and how they affect travel time is not publicly available and does not concern the scope of our research, according to several

Table 2 The algorithm used for testing the effectiveness of the approach

\begin{tabular}{|c|c|c|}
\hline \multicolumn{2}{|c|}{ Algorithm } & Calculation of the nearest $\mathrm{P} \& \mathrm{R}$ facility to each zone according to parameters \\
\hline \multicolumn{2}{|l|}{ Input: } & City zones' spatial data, P\&R locations data, set of trip-generating points for each zone. \\
\hline \multicolumn{2}{|c|}{ Output: } & Nearest P\&R facility to each zone for each weekday and each metric. \\
\hline \multicolumn{2}{|c|}{ External sources: } & Routing engine with traffic calculation sub-system. \\
\hline \multirow{5}{*}{ Steps: } & 1: & Read the data, create appropriate data structures; \\
\hline & 2: & $\begin{array}{c}\text { For each trip-generating point in each zone, calculate each metric to each of the P\&R locations for each day } \\
\text { using the appropriate routing engine. }\end{array}$ \\
\hline & 3: & For all the metrics for each zone and day, calculate the average values. \\
\hline & 4: & Compare the averages and find for each zone the nearest P\&R according to each metric for each weekday. \\
\hline & 5: & Include the results calculated in matrices and provide them to the user in a human-readable form. \\
\hline
\end{tabular}


credible sources, it is considered that both historical and live crowdsourced data are included in the calculations. While utilizing such services in traffic calculation models is not very common, several studies (Hofstede and Fioreze, 2009; Yulianto and Setiono, 2017; Wang and Xu, 2011; Fairfield and Urmson, 2011; Tostes et al., 2013) have shown up in the last 12 years that showcase useful results. An indicative example of a study that has been well-received by the scientific community and uses the same service is the article by Wang and $\mathrm{Xu}$ (2011), who use Google Maps API to calculate the travel time between sets of origins and destinations in a transportation network (O-D Matrix). In the same paper, four overall advantages are provided for using such a service instead of other traditional approaches that require data preparation (of possibly outdated data) and the use of GIS software to perform the same type of calculations in networks.

\section{Case study}

\subsection{The case study of the method and the algorithm on} Cuenca, Ecuador

After the implementation of the above algorithm in Python programming language, and by using the suitable software libraries and Application Programming Interfaces (APIs), we tested our method on data from the mid-sized city of Cuenca, Ecuador (data are available in Sustainable Urban Mobility Plan (2015)). The spatial data for the 15 zones of Cuenca were included as well as the seven predetermined P\&R facilities as they were calculated in the work of Ortega et al. (2019).

We initially considered the sub-zones or neighborhoods, which are 982 in number as they are defined in the Cuenca SUMP (2015). Those 982 subzones/neighborhoods belong to one of the 15 administrative divisions each and contain information about their spatial setting and land use. After filtering them, as described in Subection 2.1, 655 points emerged from the filtering according to the attributes of functional land use sub-criteria. Those 655 points were attributed as residential or commercial land use in the Cuenca SUMP. The distribution of those 655 points in the 15 zones is not equal, which means that some zones may have more points, and thus subzones than others, out of this set of 655 subzones/neighborhoods.

In Fig. 3, one can notice Cuenca's subzones and their correspondence to land use, as included in Cuenca's SUMP.

For this case study, five metrics were calculated for each set of input of trip-generating points, each zone, and each weekday, as described in Section 2.2. For producing the travel time data with the different levels of traffic,

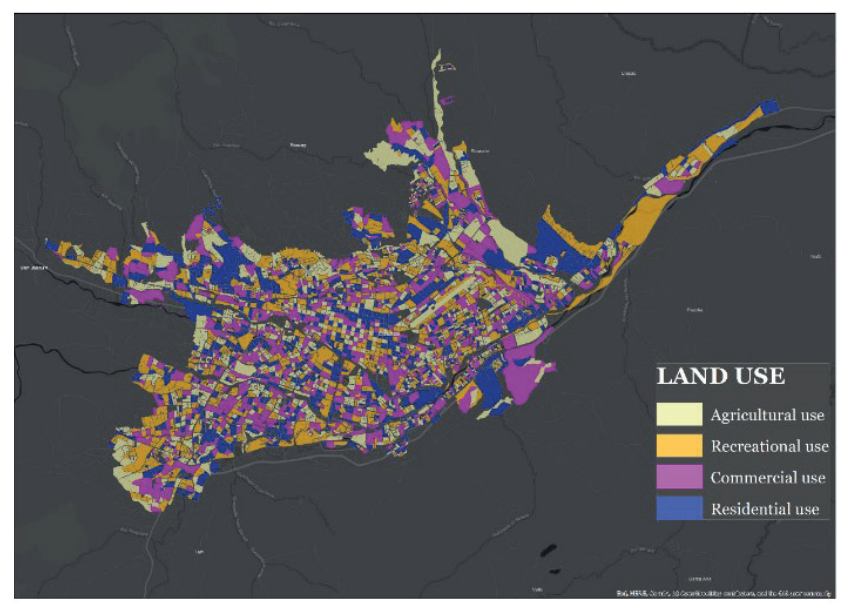

Fig. 3 Cuenca's subzones/neighborhoods classified according to land use properties, as included in the corresponding SUMP

we considered as the high traffic scenario the travels that occur at 07:30, when Cuenca residents need to attend their daily activities, and as the low-traffic scenario, the journeys that occur at 16:30. Both of the scenarios and the corresponding times of the day are included, as described in the Cuenca Sustainable Urban Mobility Plan.

The case study section includes three results tables, each corresponding to a different set of input points. As referenced in the introduction, the sets of input points are:

- Randomly generated starting points in each zone;

- Central points of subzones/neighborhoods in each zone as they are included in the corresponding SUMP;

- Central points of subzones/neighborhoods in each zone after they are filtered according to land use, as included in the corresponding SUMP.

GIS software was used for the exact decision of the coordinates of the trip-generating points, based on the boundaries of the administrative divisions as they were extracted from Cuenca SUMP. The number of points for each set of input differs. For the first set of points, the results are the same for any number of input points, and thus, the results that are listed are based on 15 random points per zone. For the second group of points, the number of points differs between the zones considered but sums up to 982 in total. For the third and final group of points, which are the ones that remain after the method is applied to 982 points, their number is 655 in total and are also unequally distributed in the zones.

\subsection{Presentation of the results}

Next, the results of this case study are given. The results tables display the nearest facility to each set of trip starting points (input points) for each zone and its included 
subzones/neighborhoods. The resulting closest facility is indicated by a capital letter that corresponds to the IDs of $P \& R$ facilities. These IDs, their corresponding and the subsequent $P \& R$ facilities, as given in Tables 3 to 5 and as elaborated previously (Ortega et al., 2019), can be found in Table 1. For each cell of each matrix, we present a quintuple of IDs with each ID corresponding to each day. For example, if the cell value is "F-F-F-F-E", this means that (for Zone 5 and the Low Traffic scenario) facility $\mathrm{F}$ was the nearest facility to trips generated from Zone 5 from Monday to Thursday, while for Friday, facility E has been calculated as the nearest facility for the same zone according to the average values of trips generated by trip generating point in Zone 5. When the IDs are the same for all of the days, then the quintuple is replaced by one ID letter that is shared for all days within a single cell.

\subsection{Discussion of the results}

In the results presented, we can see that there is an overall consistency in the P\&R system and that the nearest facility to each zone does not substantially deviate in-between the weekdays and for the different levels of traffic for each table. In other terms, the optimal trips of travelers from the zones of the city do not significantly differ concerning the temporal aspect of their journeys or the distance covered when they choose the P\&R system as previously proposed (Ortega et al., 2019). This is a great first result that indicates that the performance of the system does not

\begin{tabular}{lccccc}
\multicolumn{5}{c}{ Table 3} & $\begin{array}{c}\text { Nearest P\&R facility to each zone when considering random } \\
\text { trip-generating points in each of the 15 zones }\end{array}$ \\
\hline \multirow{4}{*}{ Zones } & \multicolumn{2}{c}{ Distance } & \multicolumn{3}{c}{ Travel time } \\
\cline { 2 - 6 } & Direct & $\begin{array}{c}\text { Road } \\
\text { network }\end{array}$ & No traffic & $\begin{array}{c}\text { Low } \\
\text { traffic }\end{array}$ & $\begin{array}{c}\text { High } \\
\text { traffic }\end{array}$ \\
\hline 1 & C & C & C & C & C \\
2 & C & C & C & C & C \\
3 & B & B & B & B & B \\
4 & F & F & F & F & F \\
5 & E & E & E & F-F-F-F-E & E \\
6 & E & E & E & E & E \\
7 & E & E & E & E & E \\
8 & E & E & E & E & E \\
9 & C & C & C & C & C \\
10 & E & D & D & D & D \\
11 & G & G & G & G & G \\
12 & F & F & F & F & F \\
13 & E & E & E & E & E \\
14 & E & E & G & G & G \\
15 & G & G & G & G & G \\
\hline
\end{tabular}

Table 4 Nearest P\&R facility to each zone when considering the 982 subzones/neighborhoods of Cuenca, Ecuador

\begin{tabular}{lccccc}
\hline \multirow{2}{*}{ Zones } & \multicolumn{2}{c}{ Distance } & \multicolumn{3}{c}{ Travel time } \\
\cline { 2 - 6 } & Direct & $\begin{array}{c}\text { Road } \\
\text { network }\end{array}$ & $\begin{array}{c}\text { No } \\
\text { traffic }\end{array}$ & Low traffic & $\begin{array}{c}\text { High } \\
\text { traffic }\end{array}$ \\
\hline 1 & C & C & C & C & C \\
2 & C & C & C & C & C \\
3 & B & B & B & B & B \\
4 & F & F & F & F & F \\
5 & E & E & E & F-E-E-E-E & E \\
6 & E & E & E & E & E \\
7 & E & E & E & E & E \\
8 & E & E & E & E & E \\
9 & C & C & D & D & D \\
10 & E & E & E & D & E-E-D-E-E \\
11 & G & G & G & G & G \\
12 & F & F & F & F & F \\
13 & E & E & E & E & E \\
14 & E & E & E & G-E-G-G-G & E \\
15 & G & G & G & G & G \\
\hline
\end{tabular}

Table 5 Nearest P\&R facility to each zone when considering 655 tripgenerating locations as they were filtered by our method

\begin{tabular}{lccccc}
\hline & \multicolumn{2}{c}{ Distance } & \multicolumn{3}{c}{ Travel time } \\
\cline { 2 - 6 } & Direct & $\begin{array}{c}\text { Road } \\
\text { network }\end{array}$ & No traffic & Low traffic & $\begin{array}{c}\text { High } \\
\text { traffic }\end{array}$ \\
\hline 1 & C & C & C & C & C \\
2 & C & C & C & C & C \\
3 & B & B & B & B & B \\
4 & F & F & F & F & F \\
5 & E & E & E & F-E-E-E-E & E \\
6 & E & E & E & E & E \\
7 & E & E & E & E & E \\
8 & E & E & E & E & E \\
9 & C & C & D & D & D \\
10 & E & E & E & E & E \\
11 & G & G & G & G & G \\
12 & F & F & F & F & F \\
13 & E & E & E & E & E \\
14 & E & E & E & G & E \\
15 & G & G & G & G & G \\
\hline
\end{tabular}

vary in considerable amounts proving its utility to be as expected and stable for several days of the week.

However, one could claim that there are several noticeable deviations. The first is related to the differences between the tables. While the results for zones 1-4, 6-8, 11-13, and 15 are the same for all three sets of input generating points and the corresponding result tables, for zones 5, 9, 10, and 14, there are noticeable differences. In more detail: 
1. For Zone 5, and for the low traffic travel time scenario, one can notice that while for Tables 4 and 5 the results are the same, for Table 3 and the random trip-generating points we have a different combination of nearest facilities to the zone. In Table 3, for most of the weekdays, Aeropuerto (F) facility is the nearest while to Zone 5, while facility E, Totoracocha, is the nearest for Friday only. Almost the opposite scenario happens for the SUMP-based points, in both cases when they are filtered or not. Aeropuerto (F) facility is the nearest only for Monday, and the Totracocha (E) for the rest of the week.

2. For Zone 9, for all of the travel time calculations (including traffic or not), substantial differences occur between the random points and the SUMPbased trip generation locations (Tables 4 and 5). The algorithm provides facility C, Feria Libre, as the nearest, when it was run for the set of random trip-generating points and facility D, Canirabamba, as the nearest for the cases when subzones/neighborhoods from the Cuenca SUMP was considered.

3. For Zone 10, and for the travel time metrics, there were differences between all of the runs of the algorithm and sets of input points. In this case, none of the three results tables resemble each other for those specific metrics. For Table 3 and the random trip-generating points, Canirabamba (D) $P \& R$ facility is indicated as the nearest facility to Zone 10 for all travel time metrics and all days. For Table 4, the results are not only different when comparing to other tables, but they are also different across the rest of the travel time metrics for Zone 10. Especially in the high traffic scenario, differences occur between the nearest facility, with Canirabamba (D) facility being the nearest for some days and Totoracocha (E) taking this position for the rest of the days. Finally, for Table 5 and the results that stem from the trip-generating points that occur from our method, Totoracocha (E) facility is indicated as the nearest facility for all the metrics and weekdays.

4. Zone 14 is the last zone for which we can notice substantial differences between the tables and sets of trip-generating points. Here, the results again differ for the travel time metrics and not the distance metrics, with Tables 4 and 5 having almost similar results and a slight deviation for only one of the weekdays. For Table 3, Parque Industrial (G) is indicated as the nearest facility for all travel time metrics, while for
Tables 4 and 5, Totoracocha (E) takes the facility's G place by being the nearest facility with some exceptions in the low-traffic scenario.

5. Another worth mentioning observation is that the results differ across the three tables, mostly concerning the travel time metrics. In other terms, while the travel time with no traffic, light traffic, or heavy traffic conditions seems to be affected by the selection of trip generating points, the direct or road network distances remain the same with only one exception, that of Zone 10 in Table 3, for which the road network distance is calculated to have Canirabamba (D) as the nearest facility. In Tables 4 and 5, the same facility is calculated to be Totoracocha (E) P\&R facility.

Finally, there is another set of observations in this comparative analysis of the result tables, and it regards the traffic. Generally, what is expected to be seen here is that there are considerable deviations between the travel times for the different levels of traffic since, as it is widely considered, in high traffic conditions, it is expected that travel times are prolonged in comparison to the low traffic and no traffic scenarios. However, in our case study, this expected phenomenon is not proven to hold. Next, we extend this list of observations:

6. In Table 3, when random trip-generation points are considered, the influence of traffic on travel times is only visible for Zone 5 and the low case scenario where there is an alternation in the result of the calculation for the nearest facility, when, for Friday, Totorococha (E) facility is calculated as the nearest instead of Aeropuerto (F) P\&R facility.

7. In Table 4, a similar deviation exists for Zone 5, with Aeropuerto facility being the nearest P\&R facility for most of the days and Totorococha facility (E) being calculated as the nearest only for the low-traffic scenario and Monday. Another difference that regards the effect of traffic is noticed at Zone 14 and the low-traffic scenario.

8. Next, in Table 5, the effect of traffic on travel times is minimal and similar to Table 4; only, in this case, Zone 10 is not affected by the levels of traffic. Zones 5 and 14 are affected by the effect of traffic with the low traffic scenario presenting differences compared to the no traffic scenario and the high traffic scenario.

In general, from observations 1 to 8 that have been listed above, one can notice what we refer to as the significant 
contributions of this work in the introduction of the article. However, observation five can serve as an extra incentive for further research in order to examine why, whether they are direct distances or road network distances, are not affected by the selection of points based on land use, when compared to the several differences ( 1 to 4 ) that concern travel time.

Worth mentioning is that many of the observations stated regard Zone 5, which is a particular type of zone. What is unique about Zone 5 is that it is a spatially centrally located zone that is close to multiple P\&R facilities. Thus, more P\&R facilities are available at a short distance (and travel time) for the inhabitants of that zone. While the results of the application of the method and the algorithm make sense from a technical viewpoint, on an operational level, Zone 5 (and Zone 6) is a particular case of a zone because they are considered as Central Business Districts (CBDs), and their inhabitants would rarely utilize their private vehicles in order to use the P\&R facilities to go to some other zone. As it is widely considered, the P\&R and the LRT systems are usually utilized by travelers whose starting points are in the outskirts of the urban periphery of a city in order to go to the CBDs. In that manner, the results calculated in the case study for CBDs (Zones 5 and 6) could be ignored.

Another aspect in which our work can be proven to be useful is the detection of the sub-optimal performance of the P\&R system along the tram corridor of a mid-sized city. Given the hypothesis that the travelers are most likely to use the P\&R facility that seems closer to their initial location when they consider the direct distance or road network distance, sometimes the other three metrics that consider the travel time with the several levels of traffic may indicate another P\&R facility than the one that is closer in terms of the former two metrics. In our case study, we can notice this phenomenon across all of the tables. In Tables 4 and 5, it is more prominent than in Table 3. An enlightening example would be the case of Zone 9 across all tables. While in Table 3, Feria Libre (C) P\&R facility is the nearest facility according to all metrics, in Tables 4 and 5, P\&R facility Feria Libre (C) is the nearest for the first two metrics (direct and road network distance) and Canirabamba (D) P\&R facility is the nearest for all of the travel time metrics. If this kind of effect can be seen in several multiple zones, then the P\&R system may not be designed for optimal performance and accessibility, and if it is established, the proper type of guidance should be given to travelers in order to use the most suitable P\&R facility. Also, these kinds of observations can be combined and be proven useful for studies (Zhou et al., 2019a) that assess the demand, the accessibility, or the critical distances around tram, or other LRT, stations according to parameters (travel purpose, land use, psychological factors).

\section{Conclusion}

The work presented in this article studies $P \& R$ systems and P\&R mode trips and their relationship with land use, traffic, and their trip starting locations. The motivation for this work stems from several surveys in the literature that connect the residential and commercial land use attributes with the use of private vehicles, parking demand, and P\&R mode. In order to prove that land use is a significant factor in the outcome of quantitative calculations and studies that regard $P \& R$ as a system or as a mode of transport, we introduce an algorithm and apply it in combination with our method to a case study for the medium-sized city of Cuenca, Ecuador. While the case study proves the expected role of land use, it also enables the derivation of insights about traffic in middle-sized cities. Based on the results, the overall contribution of this article can be summed up in three points:

1. Through an indicative quantitative case study, we show that the results, when studying $P \& R$ mode trips, can differ based on the input of trip-generating points when they are filtered according to land use. Thus, the study of P\&R mode trips is based on the effective selection of trip starting locations with land use being the principal criterion of this selection;

2. We have introduced a method for the effective selection of trip-generating locations (i.e., points) that produce P\&R mode trips. The selection of points occurs when, from an initial set of sub-zones/neighborhoods as included in SUMPs, we filter out the locations that will not produce $\mathrm{P} \& \mathrm{R}$ mode trips according to functional land use that is specified for this location in corresponding SUMPs. The method itself is reproducible for several urban environments and can be used in other related studies;

3. Finally, we show that the effect of traffic on the ridership of the P\&R mode system can be negligible for a medium-sized city like Cuenca, Ecuador.

Regarding the last contribution, this overall effect of traffic occurs only for the mid-sized city of Cuenca and cannot be generalized for all cases of urban environments. Further research, which is enabled by applying our algorithm to different cities, is required in order to support this claim to a greater extent. 
On the whole, by coming up with this method, we aimed to produce a way of considering the demand for travel with P\&R mode in an effective and reproducible way. We hope that with the method presented, further research will be enabled on P\&R systems, which are needed to be further developed in modern urban environments. However, we know that our method is data-intensive and requires the researchers to have full access to SUMPs or survey data for the city that will be studied. As a first future step, we consider the execution of surveys that will allow the functional land use and purpose for trip criteria to be included in the method. This extra layer of filtering by the trip purpose criterion will enable us to keep even more precise trip-generating locations. The built environment and socio-economic aspects of $P \& R$ mode usage should also be studied.

The algorithm for the study of the effect of traffic on the choices of travelers concerning the P\&R mode and their optimal trips from the several sub-zones/neighborhoods of a city to the $P \& R$ facilities is also a reproducible approach.

\section{References}

Abdul Hamid, N., Mohamad, J., Karim, M. R. (2008) "Travel Behaviour of the Park and Ride Users and the Factors Influencing the Demand for the Use of the Park and Ride Facility", presented at EASTS International Symposium on Sustainable Transportation incorporating Malaysian Universities Transport Research Forum Conference 2008 (MUTRFC08), Johor Bahru, Malaysia, August, 12-13, 2008.

Adnan, S. A. A. Syed, Hamsa, A. A. K. (2013) "Evaluating the parking demand at Park and Ride facility at Putrajaya public transportation Terminal", In: The 10th International conference of Eastern Asia Society for Transportation Studies, Taipei, Taiwan, 9, Article number: 14.

Aguiléra, A., L'Hostis, A., Haon, S. (2013) "Land Use and Transport Interactions", European Road Transport Research Advisory Council, [online] Available at: https:/www.ertrac.org/uploads/ documents_publications/Other/luti_initiative_final_82.pdf [Accessed: 31 August 2019]

American Association of State Highway and Transportation Officials "Guide for High-Occupancy Vehicle (HOV) Facilities", [online] Available at: www.transportation.org [Accessed: 31 August 2019]

Bakogiannis, E., Kyriakidis, C., Siti, M. (2018) "Land Use and Transportation: Identifying the relationship between parking and land use in the Municipality of Zografou, Athens", International Journal of Real Estate and Land Planning, 1(2008), pp. 260-267.

Bast, H., Delling, D., Goldberg, A., Müller-Hannemann, M., Pajor, T., Sanders, P., Wagner, D., Werneck, R. F. (2016) "Route Planning in Transportation Networks", In: Kliemann L., Sanders P. (eds.) Algorithm Engineering. Lecture Notes in Computer Science, Springer, Cham, Switzerland, pp. 19-80. https://doi.org/10.1007/978-3-319-49487-6_2
As a future research direction, we are considering the inclusion of traffic estimation models in the algorithm and its combination with open-source routing engines in order to calculate attributes of trips even more accurately.

Overall, as a final consideration, we would like to point out the importance of the inclusion of traffic and land use in mathematical models when they are developed and used for the calculation of optimal locations of $\mathrm{P} \& \mathrm{R}$ systems. Ignoring those parameters of $\mathrm{P} \& \mathrm{R}$ systems in their design or implementation phases can lead to undesirable results.

\section{Acknowledgment}

The authors are grateful to the Cuenca Municipality for providing us with the data from the Sustainable Urban Mobility Plan. The authors would like to thank colleagues within the Department of Transport Technology and Economics of the Faculty of Transportation Engineering and Vehicle Engineering of the Budapest University of Technology and Economics for their useful comments and related discussions during this study.

Bolger, D., Colquhoun, D., Morrall, J. (1992) "Planning and Design of Park-and-Ride Facilities for the Calgary Light Rail Transit System", In: Transportation Research Record 1361, TRB, National Research Council, Washington, DC, USA, pp. 141-148.

Cairns, M. R. (1998) "The Development of Park and Ride in Scotland", Journal of Transport Geography, 6(4), pp. 295-307. https://doi.org/10.1016/S0966-6923(98)00016-7

Douglass, M., Abley, S. (2001) "Trips and parking related to land use", NZ Transport Agency, Wellington, N.Z., New Zealand.

Esenbuğa, Ö. G., Akoğuz, A., Çolak, E., Varol, B., Erol, B. (2016) "Comparison of principal geodetic distance calculation methods for automated province assignment in Turkey", In: 16th International Multidisciplinary Scientific GeoConference SGEM2016, Informatics, Geoinformatics and Remote Sensing, Albena Resort, Bulgaria, pp. 141-148. https://doi.org/10.5593/SGEM2016/B22/S09.019

Fairfield, N., Urmson, C. (2011) "Traffic Light Mapping and Detection", In: 2011 IEEE International Conference on Robotics and Automation, Shanghai, China, pp. 5421-5426. https://doi.org/10.1109/ICRA.2011.5980164

Farhan, B. (2003) "Evaluation, Modeling and Policy Assessment for Park-and-Ride Services as a Component of Public Transportation", PhD Dissertation, The Ohio State University.

Farhan, B., Murray, A. T. (2005) "A GIS-Based Approach for Delineating Market Areas for Park and Ride Facilities", Transactions in GIS, 9(2), pp. 91-108. https://doi.org/10.1111/j.1467-9671.2005.00208.x

Farhan, B., Murray, A. T. (2008) "Siting Park-and-Ride Facilities Using a Multi-Objective Spatial Optimization Model", Computers and Operations Research, 35(2), pp. 445-456. https://doi.org/10.1016/j.cor.2006.03.009 
Google Inc. n.d. "Google Maps Directions API Service", [online] Available at: https:/developers.google.com/maps/documentation/ directions/start [Accessed: 31 August 2019.]

Hermida, M. A., Hermida, C., Cabrera, N., Calle, C. (2015) "La Densidad Urbana Como Variable de Análisis de La Ciudad. El Caso de Cuenca, Ecuador" (Urban Density as a Variable for City Analysis. The Case of Cuenca, Ecuador), Revista EURE - Revista de Estudios Urbano Regionales, 41(124), pp. 25-44. (in Spanish) https://doi.org/10.4067/S0250-71612015000400002

Higgins, C., Ferguson, M., Kanaroglou, P. (2014) "Light Rail and Land Use Change: Rail Transit's Role in Reshaping and Revitalizing Cities", Journal of Public Transportation, 17(2), pp. 93-112. https://doi.org/10.5038/2375-0901.17.2.5

Hofstede, R., Fioreze, T. (2009) "SURFmap: A Network Monitoring Tool Based on the Google Maps API", In: 2009 IFIP/IEEE International Symposium on Integrated Network Management, New York, NY, USA, pp. 676-690. https://doi.org/10.1109/INM.2009.5188876

Knight, R. L., Trygg, L. L. (1977) "Land Use Impacts of Rapid Transit: Implications of Recent Experience", Final report. United States. https://doi.org/10.2172/5924536

Lam, W. H. K., Li, Z. C., Huang, H. J., Wong, S. C. (2006) "Modeling time-dependent travel choice problems in road networks with multiple user classes and multiple parking facilities", Transportation Research Part B: Methodological, 40(5), pp. 368-395. https://doi.org/10.1016/j.trb.2005.05.003

Lopez, B. E., Magliocca, N. R., Crooks, A. T. (2019) "Challenges and Opportunities of Social Media Data for Socio-Environmental Systems Research", Land, 8(7), Article number: 107. https://doi.org/10.3390/land8070107

Milosavljevic, N., Simicevic, J. (2019) "Sustainable Parking Management: Practices, Policies, and Metrics", Elsevier, Amsterdam, Netherland. https://doi.org/10.1016/C2017-0-03917-4

Noel, E. C. (1988) "Park-and-Ride: Alive, Well, and Expanding in the United States", Journal of Urban Planning and Development, 114(1), pp. 2-13. https://doi.org/10.1061/(ASCE)0733-9488(1988)114:1(2)

Ortega, J., Tóth, J., Péter, T. (2019) "Estimation of parking needs at light rail transit system stations", presented at Conference on Transport Sciences, Gyor, Hungary, March, 21-22, 2019.

Péter, T., Fazekas, S. (2014) "Determination of Vehicle Density of Inputs and Outputs and Model Validation for the Analysis of Network Traffic Processes", Periodica Polytechnica Transportation Engineering, 42(1), pp. 53-61. https://doi.org/10.3311/PPtr.7282

Rio Metro Regional Transit District (2012) "Park and Ride Users Survey: Summary Report", [online] Available at: https://www.riometro. org/ [Accessed: 31 August 2019.]

Rodrigue, J.-P., Comtois, C., Slack, B. (2016) "The Geography of Transport Systems", Routledge, London, UK. https://doi.org/10.4324/9781315618159

Saharidis, G. K. D., Rizopoulos, D., Fragkogios, A., Chatzigeorgiou, C. (2017) "A hybrid approach to the problem of journey planning with the use of mathematical programming and modern techniques", Transportation Research Procedia, 24, pp. 401-409. https://doi.org/10.1016/j.trpro.2017.05.094
Song, Z., He, Y., Zhang, L. (2017) "Integrated planning of park-and-ride facilities and transit service", Transportation Research Part C: Emerging Technologies, 74, pp. 182-195.

https://doi.org/10.1016/j.trc.2016.11.017

Tostes, A. I. J., Duarte-Figueiredo, F. de L. P., Assunção, R., Salles, J., Loureiro, A. A. F. (2013) "From data to knowledge: City-wide traffic flows analysis and prediction using bing maps", In: UrbComp '13: Proceedings of the 2nd ACM SIGKDD International Workshop on Urban Computing, Chicago, IL, USA, pp. 1-8. https://doi.org/10.1145/2505821.2505831

TriMet (2011) "The OpenTripPlanner Project", [online] Available at: https://trimet.org/mod/docs/OTP\%20Final\%20Report\%20-\%20 Metro\%202009-2011\%20RTO\%20Grant.pdf [Accessed: 31 August 2019]

Un-Habitat (2013) "Planning and Design for Sustainable Urban Mobility", Routledge, London, UK. https://doi.org/10.4324/9781315857152

Wang, F., Xu, Y. (2011) "Estimating O-D travel time matrix by Google Maps API: implementation, advantages, and implications", Annals of GIS, 17(4), pp. 199-209. https://doi.org/10.1080/19475683.2011.625977

Weyer, Bezerra, Vos (2019) "Participatory Mapping in a Developing Country Context: Lessons from South Africa", Land, 8(9), Article number: 134. https://doi.org/10.3390/land8090134

Whitsel, E. A. (2004) "Accuracy and Repeatability of Commercial Geocoding", American Journal of Epidemiology, 160(10), pp. 1023-1029.

https://doi.org/10.1093/aje/kwh310

Winarno, E., Hadikurniawati, W., Rosso, R. N. (2017) "Location based service for presence system using haversine method", In: 2017 International Conference on Innovative and Creative Information Technology (ICITech), Salatiga, Indonesia, pp. 1-4. https://doi.org/10.1109/INNOCIT.2017.8319153

Yin, C., Shao, C., Wang, X. (2018) "Built Environment and Parking Availability: Impacts on Car Ownership and Use", Sustainability, 10(7), Article number: 2285. https://doi.org/10.3390/su10072285

Yulianto, B., Setiono (2017) "Web Application and Database Modeling of Traffic Impact Analysis Using Google Maps", In: AIP Conference Proceedings 1855, Article number:060002. https://doi.org/10.1063/1.4985525

Zhou, Y., Qian, C., Xiao, H., Xin, J., Wei, Z., Feng, Q. (2019a) "Coupling Research on Land Use and Travel Behaviors Along the Tram Based on Accessibility Measurement-Taking Nanjing Chilin Tram Line 1 as an Example", Sustainability, 11(7), Article umber: 2034. https://doi.org/10.3390/su11072034

Zhou, Y., Li, Y., Hao, M., Yamamoto, T. (2019b) "A System of Shared Autonomous Vehicles Combined with Park-And-Ride in Residential Areas", Sustainability, 11(11), Article number: 3113. https://doi.org/10.3390/su11113113 